\title{
S.
}

Питухина М.A.

\section{К ВОПРОСУ О СЕКЬЮРИТИЗАЦИИ МИГРАЦИИ В РОССИИ}

Аннотация: Работа посвящена исследованию актуального вопроса секьюритизации миграционных потоков в России на современном этапе. В настоящее время дискурс секьюритизации миграции в стране достиг своего апогея - необходимы меры, нацеленные на уменьшение возможных угроз наииональной безопасности и повышение качества человеческого капитала. За последние 2 года были предприняты кардинальные меры по десекьюритизачии миграции, однако, по мнению автора, их недостаточно. В свою очередь, это доказывает тот факт, что миграчионная политика России переживает существенные трансформачии. Методология исследования базируется на подходе к секьюритизации миграции, реализуемом учеными из Копенгагенского института исследования мира. С иелью обоснования результатов исследования были применены методы типологизации, сравнения и метод экспертных оценок. Были определены три меры, которые приведут к десекьюритизации миграции. Полученные результаты поспособствуют оптимизации миграционной политики, повышению качества человеческого капитала и десекьюритизации миграчии не только в краткосрочном, но среднесрочном и долгосрочном периодах. Опыт ведущих стран ОЭСР является чрезвычайно важным; его использование ляжет в основу разработки рекомендаций для органов, осуществляющих регулирование в сфере миграционной политики в России.

Ключевые слова: секьюритизация миграции, миграционная политика, квалифицированная миграчия, человеческий капитал, тренды, ОЭСР, инноваџионные меры, десекьюритизация, снижение угроз, мягкая безопасность.

Концепции государственной миграционной политики РФ на период до 2025 года прописываются 3 фундаментальные цели государственной миграционной политики ${ }^{1}$ :

а) обеспечение национальной безопасности Российской Федерации, максимальная защищенность, комфортность и благополучие населения Российской Федерации;

б) стабилизация и увеличение численности постоянного населения Российской Федерации;

в) содействие обеспечению потребности экономики Российской Федерации в рабочей силе, модернизации, инновационном развитии и повышении конкурентоспособности ее отраслей.

Очевидно, что гражданин является наивысшим приоритетом в России. В перечисленных принципах

\footnotetext{
1 Концепция государственной миграционной политики РФ на период до 2025 года URL: http://kremlin.ru/acts/15635 (дата обращения: 1.11.2013)
}

Концепции о мигрантах не сказано ни слова. Тем не менее, уже в настоящее время миграционный прирост в России не замещает естественную убыль населения (Рисунок 1). Это вполне естественно, т.к. Россия - страна с небольшой долей мигрантов относительно коренного населения - 8,9\% . Для сравнения доля мигрантов в Люксембурге составляет $37.6 \%$, в Швейцарии - 26.6\%, в Германии - 13\%, в Швеции - $11.5 \%$. По прогнозам Росстата, к 2030 году население России уменьшится до 139 миллионов человек; люди старше 65 лет составят четверть населения страны ${ }^{2}$. Очевидно, что в таких условиях в ближайшие десятилетия необходимость в мигрантах только возрастет.

В России в течение последних 2 лет дискурс секьюритизации миграции достиг своего апогея.

\footnotetext{
2 Предполагаемая численность до 2030 года. Статистический бюллетень / Федеральная служба государственной статистики. Москва. - 2010. - сc.5-225.
} 


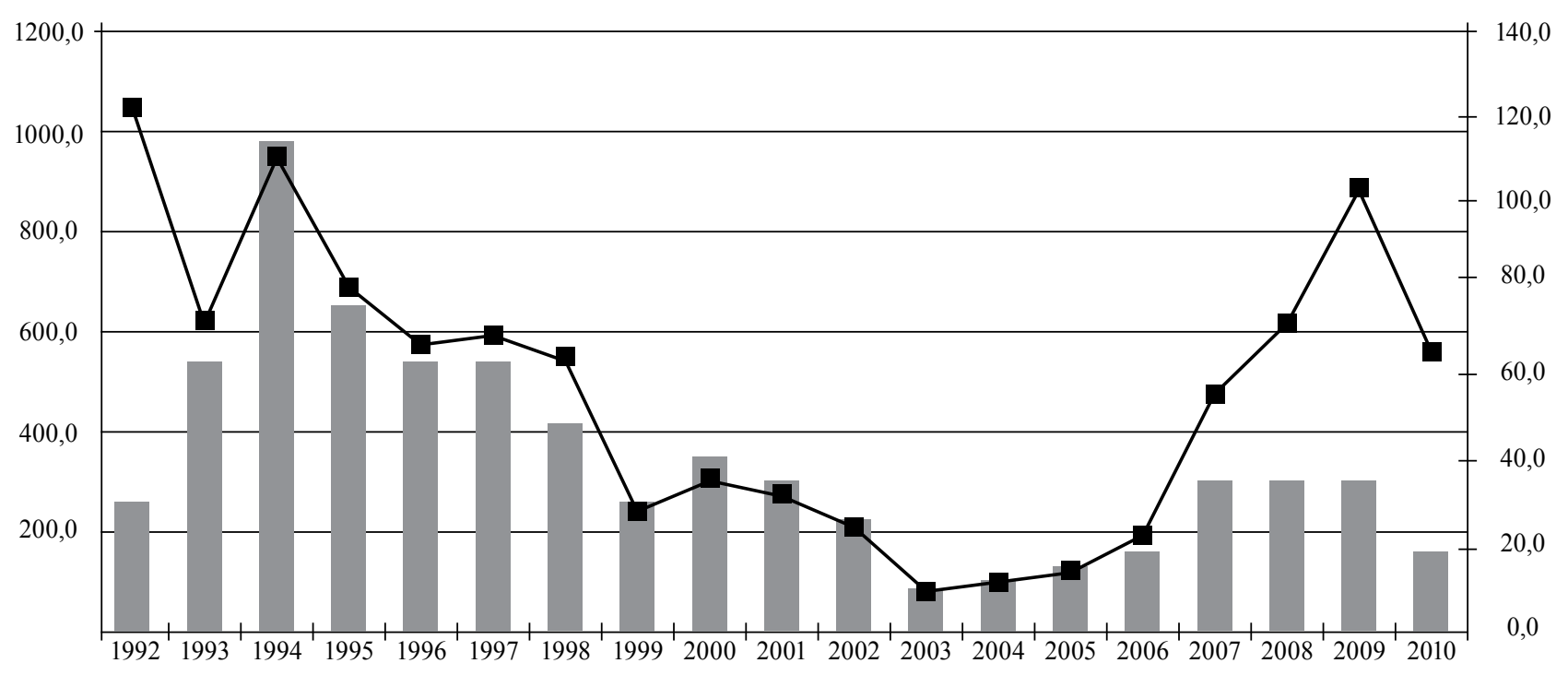

Рис. 1. Миграционный прирост (тыс человек) и замещение естественной убыли миграционным приростом (\%), Россия, 1992-2009

(Стратегия-2020: Новая модель роста - новая социальная политика. 2011.

Систем.требования: Adobe Acrobat. URL: http://www.kommersant.ru/Docs/2011/2011d153-doklad.pdf (дата обращения: 1.11.2013)

В Послании Федеральному Собранию от 2013 года В. В. Путин подчеркнул, что «Ещё одна сложная проблема, связанная с состоянием рынка труда. Это иностранная трудовая миграция. Отсутствие должного порядка не только деформирует структуру занятости, но и вызывает дисбалансы в социальной сфере, провоцирует национальные конфликты, обостряет криминогенную обстановку» ${ }^{3}$. Таким образом, на повестке дня России остро стоит вопрос о секьюритизации миграции - необходимы меры, нацеленные на уменьшение возможных угроз национальной безопасности и повышение качества человеческого капитала.

В качестве интересного методологического подхода выделяем работы ученых из Копенгагенского института исследования мира (Copenhagen Peace Research Institute) Уле Вивера и Барри Бузана. Их совместная работа 1998 года «Безопасность - новые рамки анализа» посвящена концепции «мягкой» безопасности, согласно которой безопасность стала рассматриваться не только как сфера военных угроз национальным интересам государству ${ }^{4}$. Среди «новых» угроз учеными выделяются миграция (не-

\footnotetext{
3 Послание Президента Федеральному Собранию 2013 года URL:http://www.kremlin.ru/news/19825 (дата обращения: 6.02.2014)

4 Buzan B., Waever O, de Wilde J. Security: A New Framework for Analysis. London, 1998.
}

легальная, бесконтрольная), неблагоприятная экологическая среда, загрязнение окружающей среды, преступность, незаконный оборот наркотиков и т.д. Именно Вивер и Бузан ввели понятие «секьюритизация миграции». Согласно теории секьюритизации, какое-либо явление может стать аспектом безопасности только посредством некоторых действий, результатом которых является то, что это явление начинает восприниматься обществом как угроза его существованию, а также существованию и благосостоянию государства в целом.

Таким образом, проводимое Бузаном и Вивером исследование дает основу для анализа тенденций секьюритизации миграции в мире и в России, в частности.

Нельзя не согласиться, что ряд поведенческих стереотипов мигрантов представляет потенциальную угрозу безопасности России:

- совершение большого количества правонарушений (особенно характерно для мегаполисов);

- желание мигрантов жить «в тени» (наличие феодального мышления);

- ошибочное восприятие России — «СССР был моим домом»;

- низкий уровень грамотности (доминирование родного языка мигрантов над русским; отсутствие образования или доминирование НПО надо СПО и ВПО, что подтверждают данные Таблицы 1). 


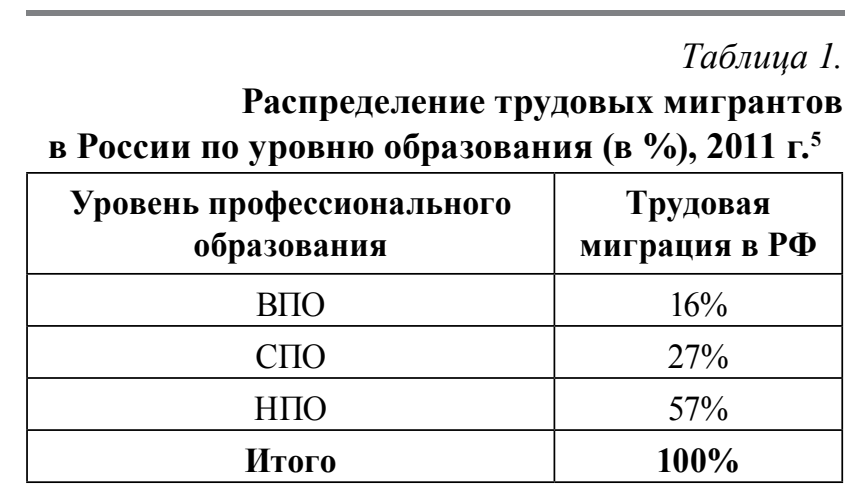

Неудивительно, что в настоящее время в России активно предпринимаются усилия, ориентированные на снижение возможных угроз национальной безопасности от миграции:

1. В мае 2012 года после подписания Указа «Об обеспечении межнационального согласия» в стране открылось 250 центров сертификации мигрантов в 83 регионах страны. Начиная с 1 января 2013 годы, все мигранты в обязательном порядке сдают экзамен по русскому языку6. С 2015 года мигранты будут сдавать экзамены по истории Отечества и основам российского законодательства.

2. В мае 2013 года Распоряжением Правительства РФ № 848-р утвержден перечень территорий приоритетного заселения - территорий, стратегически важных для России в рамках Государственной Программ добровольного переселения в РФ соотечественников, проживающих за рубежом. С 2013 года территориями приоритетного заселения РФ стали Бурятия, Забайкальский, Камчатский, Приморский, Хабаровский края, Амурская, Иркутская, Магаданская, Сахалинская области и Еврейская автономная область. Таким образом, мигрантам на этих территориях предоставляются существенные послабления при выдаче гражданства, а также ряд государственных гарантий и социальная поддержка7.

3. Новейшие изменения в миграционном законо-

\footnotetext{
5 Парикова Н.В., Сигова С.В. Влияние зарубежной трудовой миграции // Служба занятости. — 2012. — №1 - — С. 64-69.

6 Языковые тесты были разработаны крупнейшими вузами страны - МГУ, СПбГУ и РУДН. Тесты включают в себя аудирование, грамматику и разговорную практику. 850 слов лингвистический минимум, которым должны обладать мигранты, приезжающие в страну.

7 Распоряжение Правительства РФ № 848-р от 27 мая 2013 года URL: http://www.rg.ru/2013/06/03/zaselenie-site-dok.html (дата обращения: 1.11.2013); Государственная Программа добровольного переселения в Россию URL:http://www.rusinkg.ru/ pereselenie/content/4-pereselenie/23-gosprogramma-dobrovolnogopereseleniya-v-rossiyu\%E2\%99\%9 (дата обращения: 1.11.2013)
}

дательстве, вступившие в силу с 9 августа 2013 года, также помогут минимизировать угрозы от миграции. В 4 субъектах РФ (Москве, Санкт-Петербурге, Московской и Ленинградской областях) действует принудительное выдворение мигрантов, в то время как самостоятельное выдворение на доверии пока еще остается на территории других субъектов РФ. С 2013 вводится градация запрещения въезда на 3 и 5 лет в зависимости от типа правонарушения. Штрафные санкции за правонарушения в этих 4 субъектах в 2 раза выше по сравнению с другими регионами России. С 5 ноября 2013 для мигрантов вводятся обязательные водительские права российского образца.

Перечисленные выше меры последних двух лет, с одной стороны, свидетельствуют об ужесточении миграционного законодательства, с другой стороны, приводят к уменьшению возможных угроз национальной безопасности (десекьюритизации миграции) и повышению качества человеческого капитала в стране. Однако, также очевидно, что указанных мер недостаточно. В настоящее время необходимо расширять перечень мер, в связи с чем считаем важным предложить следующее.

1.Опыт США и Германии является показательным в части привлечения потоков квалифицированной миграционной силы, поскольку Россия занимает второе место в мире по количеству мигрантов в стране - 12.3 миллиона после США (48 миллионов) и, опережая Германию $\left(10.8\right.$ миллионов) ${ }^{8}$. Так, например, американские сенаторы недавно подготовили законопроект о мигрантах, который позволит выдавать вид на жительство тем, кто закончил магистратуру в американском вузе или получил в США ученую степень. Введенная в августе 2012 года система голубых карт Германии дает возможность гражданам не из ЕС жить и работать в течение 4 лет в Германии и других странах $\mathrm{EC}^{9}$. Требования к обладателям голубых карт - университетское образование и знание немецкого языка; трудовой контракт с годовым доходом €46.400 (3.867 евро

\footnotetext{
8 World Development Report // World Bank. 2013.URL:http:// wdronline.worldbank.org/worldbank/a/c.html/world development_report_2013/abstract/WB.978-0-8213-9575-2. abstract (дата обращения: 1.11.2013)

9 Germany's blue card scheme// Bluecard-EU. 2013. URL:http:// www.bluecard-eu.de/eu-blue-card-germany/ (дата обращения: 1.11.2013)
} 


\section{Внутренний контур национальной безопасности}

в месяц); трудовой контракт по дефицитным профессиям на рынке труда (ученый, математик, инженер, доктор, программист) с годовым доходом €36.192 (3.016 евро в месяц). В настоящее время мигрантами в Германии получено свыше 4000 голубых карт. Таким образом, привлечение квалифицированной миграции в Россию является оправданной мерой и, в конечном итоге, приведет к повышению человеческого капитала в стране, а, следовательно, и к десекьюритизации миграции.

2.Десекьюритизация миграции возможна также с помощью эффективного использования результатов мониторинга за мигрантами по примеру Финляндии. Так, персональные данные о мигрантах (возраст, пол, страна происхождения, страна эмиграции, религия, наличие брака, дата въезда в страну и т.п.), получаемые из различных источников, аккумулируются Информационной Системе «Население» Центра Регистрации Населения (ИС) при Статистическом Агентстве Финляндии ${ }^{10}$. Информация по мигрантам стекается в ИС из церковных приходов различных конфессий, больниц, миграционной службы Финляндии. В Финляндии для получения работы или медицинской помощи мигранту необходима идентификационная карта для этого, в свою очередь, каждый мигрант обязан пройти процедуру обязательной регистрации в ИС. Ежегодно сотрудниками, обслуживающими Информационную Систему «Население», проводится выборка по мигрантам и проверяется их адрес проживания. В 2011 году у 99\% мигрантов адрес оставался прежним. Каждый месяц ИС формирует окончательные отчеты по изменениям за месяц («Population statistics service»). В конце каждого квартала ИС предоставляет предварительную статистику по изменениям в населении за год («Quarterly population statistics»). Публикуется статистика по мигрантам ежегодно: в электронном виде в мае и в бумажном - в июне каждого года («Population structure and vital statistics by municipality»).

3.Еже одна мера, которая существенно поможет минимизировать угрозы от миграции, это введение системы слежения за внешними границами России с помощью спутников, вертолетов и беспилотников по примеру системы Eurosur

10 Statistics Finland URL:http://www.stat.fi/tup/suoluk/suoluk vaesto_en.html (дата обращения: 1.11.2013) стран $\mathrm{EC}^{11}$. Основные задачи системы Eurosur сокращение числа нелегальных мигрантов, попадающих в ЕС необнаруженными, уменьшение количества жертв среди нелегальных мигрантов на море и укрепление внутренней безопасности EC . K Eurosur уже подключились 18 стран Союза и Норвегия. С декабря 2014-го к ней должны присоединиться остальные страны ЕС и государства - члены Шенгенского соглашения. Главному отделению подчиняются 8 коордиционных центров в восьми странах (Португалия, Испания, Франция, Италия, Греция, Алжир, Марокко и Ливия). Расходы на Eurosur с 2014 по 2020 годы составят 244 миллиона евро или 40,5 миллионов в год.

В ходе обследования были сделаны следующие важные выводы, которые необходимо учитывать России при оптимизации миграционной политики и повышении качества человеческого капитала не только в краткосрочном, но среднесрочном и долгосрочном периодах.:

- Опыт проводимой политики Германии и США по интеграции квалифицированных мигрантов является чрезвычайно важным, т.к. поспособствует повышению человеческого капитала в стране. Подвижки на данном направлении имеются. В Послании Федеральному Собранию РФ в 2013 году В.Путин отмечает, что «необходимо стимулировать приток в Россию прежде всего профессиональных, образованных специалистов, знающих русский язык, близких к нашей культуре, а патент должен стать экономическим инструментом регулирования миграционных потоков и действовать только в том регионе, где он приобретён».

- Опыт по реализации эффективного мониторинга мигрантов Финляндии также является чрезвычайно актуальным для России. Согласно Концепции общественной безопасности в Российской Федерации, утвержденной 20 ноября 2013 года, «предполагается формирование в России автоматизированной системы оформления и выдачи миграционных карт с одновременным внесением информации, содержащейся в них, в государственную информационную систему миграционного учёта и совершенствование межведомственного взаимодействия, в том числе

11 EUROSUR URL: http://frontex.europa.eu/intelligence/eurosur (дата обращения: 6.02.2014) 
обмена информацией на внутригосударственном уровне, а также взаимодействия с компетентными органами иностранных государств по вопросам противодействия незаконной миграции» ${ }^{12}$.

- На границах России в настоящее время фактически не работает миграционный учет.
Предложенная выше мера по введению системы, аналогичной EUROSUR, позволит иметь четкие представления о пересечениях государственной границы мигрантами, что, особенно, является актуальным для Дальнего Востока.

\section{Библиография}

1. Государственная Программа добровольного переселения в Россию URL:http://www.rusinkg.ru/pereselenie/ content/4-pereselenie/23-gosprogramma-dobrovolnogo-pereseleniya-v-rossiyu\%E2\%99\%9 (дата обращения: 1.11.2013)

2. Концепция государственной миграционной политики РФ на период до 2025 года URL: http://kremlin.ru/ acts/15635 (дата обращения: 1.11.2013)

3. Концепция общественной безопасности в PФ URL: http://www.kremlin.ru/acts/19653 (дата обращения: 6.02.2014)

4. Парикова Н.В., Сигова С.В. Влияние зарубежной трудовой миграции // Служба занятости. — 2012. №1. - С. 64-69.

5. Послание Президента Федеральному Собранию 2013 года URL:http://www.kremlin.ru/news/19825 (дата обращения: 6.02.2014)

6. Предполагаемая численность до 2030 года. Статистический бюллетень / Федеральная служба государственной статистики. Москва. - 2010. - сc.5-225.

7. Распоряжение Правительства РФ № 848-р от 27 мая 2013 года URL: http://www.rg.ru/2013/06/03/zaseleniesite-dok.html (дата обращения: 1.11.2013)

8. Стратегия-2020: Новая модель роста - новая социальная политика. 2011. Систем. требования: Adobe Acrobat. URL: http://www.kommersant.ru/Docs/2011/2011d153-doklad.pdf (дата обращения: 1.11.2013)

9. Buzan B., Waever O, de Wilde J. Security: A New Framework for Analysis. London, 1998.

10. EUROSUR URL: http://frontex.europa.eu/intelligence/eurosur (дата обращения: 6.02.2014)

11. Germany's blue card scheme // Bluecard -EU. 2013. URL:http://www.bluecard-eu.de/eu-blue-card-germany/ (дата обращения: 1.11.2013)

12. Statistics Finland URL:http://www.stat.fi/tup/suoluk/suoluk_vaesto_en.html (дата обращения: 1.11.2013)

13. World Development Report // World Bank. 2013.URL:http://wdronline.worldbank.org/worldbank/a/c.html/ world_development_report_2013/abstract/WB.978-0-8213-9575-2.abstract (дата обращения: 1.11.2013)

14. Волох В.А., Герасимова И.В. Экономические эффекты от реализации государственной миграционной политики Российской Федерации. // NB: Экономика, тренды и управление. - 2014. — 1. — C. 1-12. URL: http://www.e-notabene.ru/etc/article_9629.html

15. Волох В.А. Миграционная политика: реадмиссия - эффективный инструмент противодействия нелегальной миграции // NB: Национальная безопасность. - 2012. - 1. — C. 255-270. DOI: 10.7256/23060417.2012.1.106. URL: http://www.e-notabene.ru/nb/article_106.html

16. Волох В.А., Володин Е.В. Новое в законодательстве о трудовой миграции: плюсы и минусы // NB: Вопросы права и политики. — 2013. — 10. - C. 93-103. URL: http://www.e-notabene.ru/lr/article_9793.html

17. Волох В.А., Суворова В.А. Концепция государственной миграционной политики России - основа миграционной безопасности страны // NB: Национальная безопасность. - 2013. - 3. — C. 1-16. URL: http:// www.e-notabene.ru/nb/article_713.html

18. Мамитова Н.В. Миграционная политика Российской Федерации: проблемы теории и практики // NB: Проблемы общества и политики. - 2013. - 6. - C. 73-104. URL: http://www.e-notabene.ru/pr/ article_532.html

12 Концепция общественной безопасности в PФ URL: http:// www.kremlin.ru/acts/19653 (дата обращения: 6.02.2014) 
19. Щупленков Н.О., Щупленков О.В. Перспективы развития миграционного права в России // NB: Проблемы общества и политики. — 2014. - 1. — C. 36-75. URL: http://www.e-notabene.ru/pr/article_10776.html

20. Волох В.А. Трудовая миграция: законодательство и политика // NB: Вопросы права и политики. — 2013. — 3. — C. 1-20. URL: http://www.e-notabene.ru/lr/article_594.html

21. Бугай Н.Ф., Чеботарева В.Г. Страницы истории немецкого крестьянства России // NB: Исторические исследования. — 2013. - 1. — C. 70-128. URL: http://www.e-notabene.ru/hr/article_603.html

22. Н. Ф. Бугай, В. Г. Чеботарева Немецкие колонисты - советские (российские) немцы: парадоксы отечественной истории // Исторический журнал: научные исследования. - 2013. - 1. - С. 33-44. DOI: 10.7256/2222-1972.2013.01.4.

23. Игонин Д.И.. Определение стратегических приоритетов в государственной миграционной политике России как превентивная мера социальной дезадаптации.. // Тренды и управление. — 2013. — № 4. — С. 41-57. DOI: 10.7256/2307-9118.2013.4.4880.

24. А.И Кириллова. Интеграция мигрантов-мусульман в российское общество. // Тренды и управление. 2013. — № 2. — C. 165-179. DOI: 10.7256/2307-9118.2013.2.5009.

25. Смирнова Е.С.. Проблемы демографической и этнокультурной безопасности в условиях высокого уровня миграции: мировой опыт. // Политика и Общество. — 2013. — № 6. - С. 687-701. DOI: 10.7256/18128696.2013.6.8602.

26. Чирков Д.К., Антонов-Романовский Г.В., Литвинов А.А.. Влияние миграционных потоков из-за рубежа на криминальную ситуацию в России. // Национальная безопасность / nota bene. — 2013. — № 3. — С. 511-515. DOI: 10.7256/2073-8560.2013.3.7627.

27. В. А. Гайкин. Полицейский профсоюз Соайкай - инструмент управления корейской диаспорой в Японии. // Исторический журнал: научные исследования. - 2013. — № 1. - C. 104-107. DOI: 10.7256/22221972.2013.01.11.

28. Р. С. Бобохонов. Миграционные процессы в Таджикистане (XX в.) и России. // Политика и Общество. 2012. 一 № 4. - С. 137-146.

29. Е.С. Смирнова. Опасность ухудшения криминогенной обстановки в связи с ростом незаконной миграции: мировой опыт. // Политика и Общество. — 2012. — № 10. — С. 49-65.

30. Ю. К. Ахатов. Сахалинская область в разрезе миграционных процессов. // Политика и Общество. — 2011. — № 12. - С. 129-136.

31. Н. А. Шмаков. Демографические рейтинги положения. Рейтинги регионов РФ по уровню миграционного прибытия/выбытия. // Национальная безопасность / nota bene. - 2011. — № 4. — C. 19-26.

\section{References}

1. Gosudarstvennaya Programma dobrovol'nogo pereseleniya v Rossiyu URL:http://www.rusinkg.ru/pereselenie/ content/4-pereselenie/23-gosprogramma-dobrovolnogo-pereseleniya-v-rossiyu $\% \mathrm{E} 2 \% 99 \% 9$ (data obrashcheniya: 1.11.2013)

2. Kontseptsiya gosudarstvennoi migratsionnoi politiki RF na period do 2025 goda URL: http://kremlin.ru/acts/15635 (data obrashcheniya: 1.11.2013)

3. Kontseptsiya obshchestvennoi bezopasnosti v RF URL: http://www.kremlin.ru/acts/19653 (data obrashcheniya: 6.02.2014)

4. Parikova N.V., Sigova S.V. Vliyanie zarubezhnoi trudovoi migratsii // Sluzhba zanyatosti. — 2012. — №1. — S. 64-69.

5. Poslanie Prezidenta Federal'nomu Sobraniyu 2013 goda URL:http://www.kremlin.ru/news/19825 (data obrashcheniya: 6.02.2014)

6. Predpolagaemaya chislennost' do 2030 goda. Statisticheskii byulleten' / Federal'naya sluzhba gosudarstvennoi statistiki. Moskva. - 2010. - ss.5-225.

7. Rasporyazhenie Pravitel'stva RF № 848-r ot 27 maya 2013 goda URL: http://www.rg.ru/2013/06/03/zaseleniesite-dok.html (data obrashcheniya: 1.11.2013)

8. Strategiya-2020: Novaya model' rosta — novaya sotsial'naya politika. 2011. Sistem.trebovaniya: Adobe Acrobat. URL: http://www.kommersant.ru/Docs/2011/2011d153-doklad.pdf (data obrashcheniya: 1.11.2013) 


\section{Национальная безопасность - № 2(31) • 2014}

9. Buzan B., Waever O, de Wilde J. Security: A New Framework for Analysis. London, 1998.

10. EUROSUR URL: http://frontex.europa.eu/intelligence/eurosur (data obrashcheniya: 6.02.2014)

11. Germany's blue card scheme// Bluecard-EU. 2013. URL:http://www.bluecard-eu.de/eu-blue-card-germany/ (data obrashcheniya: 1.11.2013)

12. Statistics Finland URL:http://www.stat.fi/tup/suoluk/suoluk_vaesto_en.html (data obrashcheniya: 1.11.2013)

13. World Development Report // World Bank. 2013.URL:http://wdronline.worldbank.org/worldbank/a/c.html/ world_development_report_2013/abstract/WB.978-0-8213-9575-2.abstract (data obrashcheniya: 1.11.2013)

14. Volokh V.A., Gerasimova I.V. Ekonomicheskie effekty ot realizatsii gosudarstvennoi migratsionnoi politiki Rossiiskoi Federatsii. // NB: Ekonomika, trendy i upravlenie. - 2014. - 1. - C. 1-12. URL: http://www.enotabene.ru/etc/article_9629.html

15. Volokh V.A. Migratsionnaya politika: readmissiya — effektivnyi instrument protivodeistviya nelegal'noi migratsii // NB: Natsional'naya bezopasnost'. — 2012. — 1. — C. 255-270. DOI: 10.7256/2306-0417.2012.1.106. URL: http://www.e-notabene.ru/nb/article_106.html

16. Volokh V.A., Volodin E.V. Novoe v zakonodatel'stve o trudovoi migratsii: plyusy i minusy // NB: Voprosy prava i politiki. — 2013. - 10. — C. 93-103. URL: http://www.e-notabene.ru/lr/article_9793.html

17. Volokh V.A., Suvorova V.A. Kontseptsiya gosudarstvennoi migratsionnoi politiki Rossii — osnova migratsionnoi bezopasnosti strany // NB: Natsional'naya bezopasnost'. - 2013. - 3. - C. 1-16. URL: http://www.e-notabene. $\mathrm{ru} / \mathrm{nb} /$ article $713 . \mathrm{html}$

18. Mamitova N.V. Migratsionnaya politika Rossiiskoi Federatsii: problemy teorii i praktiki // NB: Problemy obshchestva i politiki. — 2013. — 6. - C. 73-104. URL: http://www.e-notabene.ru/pr/article_532.html

19. Shchuplenkov N.O., Shchuplenkov O.V. Perspektivy razvitiya migratsionnogo prava v Rossii // NB: Problemy obshchestva i politiki. — 2014. - 1. - C. 36-75. URL: http://www.e-notabene.ru/pr/article_10776.html

20. Volokh V.A. Trudovaya migratsiya: zakonodatel'stvo i politika // NB: Voprosy prava i politiki. — 2013. — 3. C. 1-20. URL: http://www.e-notabene.ru/lr/article 594.html

21. Bugai N.F., Chebotareva V.G. Stranitsy istorii nemetskogo krest'yanstva Rossii // NB: Istoricheskie issledovaniya. 2013. - 1. - C. 70-128. URL: http://www.e-notabene.ru/hr/article_603.html

22. N. F. Bugai, V. G. Chebotareva Nemetskie kolonisty — sovetskie (rossiiskie) nemtsy: paradoksy otechestvennoi istorii // Istoricheskii zhurnal: nauchnye issledovaniya. - 2013. - 1. - C. 33-44. DOI: 10.7256/22221972.2013.01.4.

23. Igonin D.I.. Opredelenie strategicheskikh prioritetov v gosudarstvennoi migratsionnoi politike Rossii kak preventivnaya mera sotsial'noi dezadaptatsii.. // Trendy i upravlenie. - 2013. - № 4. - C. 41-57. DOI: 10.7256/2307-9118.2013.4.4880.

24. A.I Kirillova. Integratsiya migrantov-musul'man v rossiiskoe obshchestvo. // Trendy i upravlenie. — 2013. № 2. - C. 165-179. DOI: 10.7256/2307-9118.2013.2.5009.

25. Smirnova E.S.. Problemy demograficheskoi i etnokul'turnoi bezopasnosti v usloviyakh vysokogo urovnya migratsii: mirovoi opyt. // Politika i Obshchestvo. — 2013. — № 6. — C. 687-701. DOI: 10.7256/1812-8696.2013.6.8602.

26. Chirkov D.K., Antonov-Romanovskii G.V., Litvinov A.A.. Vliyanie migratsionnykh potokov iz-za rubezha na kriminal'nuyu situatsiyu v Rossii. // Natsional'naya bezopasnost' / nota bene. — 2013. — № 3. — C. 511-515. DOI: $10.7256 / 2073-8560.2013 .3 .7627$.

27. V. A. Gaikin. Politseiskii profsoyuz Soaikai — instrument upravleniya koreiskoi diasporoi v Yaponii. // Istoricheskii zhurnal: nauchnye issledovaniya. — 2013. — № 1. — C. 104-107. DOI: 10.7256/2222-1972.2013.01.11.

28. R. S. Bobokhonov. Migratsionnye protsessy v Tadzhikistane (XX v.) i Rossii. // Politika i Obshchestvo. — 2012. № 4. - C. 137-146.

29. E.S. Smirnova. Opasnost' ukhudsheniya kriminogennoi obstanovki v svyazi s rostom nezakonnoi migratsii: mirovoi opyt. // Politika i Obshchestvo. — 2012. — № 10. - C. 49-65.

30. Yu. K. Akhatov. Sakhalinskaya oblast' v razreze migratsionnykh protsessov. // Politika i Obshchestvo. — 2011. № 12. - C. 129-136.

31. N. A. Shmakov. Demograficheskie reitingi polozheniya. Reitingi regionov RF po urovnyu migratsionnogo pribytiya/vybytiya. // Natsional'naya bezopasnost' / nota bene. — 2011. — № 4. - C. 19-26. 